\title{
Decline of Betula ermanii with Special Reference to Ozone Concentration at Mt. Mae-Shirane, Oku-Nikko, Japan
}

\author{
${ }^{1,2}$ Y. W. Feng, ${ }^{1}$ N. Ohta and ${ }^{1}$ H. Shimizu \\ ${ }^{1}$ National Institute for Environmental Studies, 16-2 Onogawa \\ Tsukuba, Ibaraki, 305-0053, Japan \\ ${ }^{2}$ National Institute for Rural Engineering, 2-1-6 Kannondai \\ Tsukuba, Ibaraki, 305-8609, Japan
}

\begin{abstract}
During June to October 2000 and 2001 we measured the height, Diameter at Breast Height (DBH) and stand density of Betula ermanii trees at Mt. Mae-Shirane, Japan and the ozone concentration there to explore the relationship between ozone concentration and the decline of $B$. ermanii trees on the mountain. Height, DBH and stem volume were lower on the southeast-facing slope than on the northwest-facing slope. Stand density on the southeast-facing slope was 1/8 that on the northwest-facing slope. Serious forest decline was observed on the southeast-facing slope. The ozone concentration was higher on the southeast-facing slope than on the northwest-facing slope during the period of measurement. Experimental exposure of $B$. ermanii to ozone showed that at the concentration levels observed at Mt. Mae-shirane this pollutant significantly damages the growth of $B$. ermanii. It is concluded that ozone is one factor that damages the growth of B. ermanii at Mt. Mae-Shirane.
\end{abstract}

Key words: Forest Decline, Ozone Concentration, B. ermanii, Growth, Passive Sampler

\section{INTRODUCTION}

Forest decline is an important environmental problem around the world. Among many factors for the cause of damage to trees, ozone is a common, phytotoxic air pollutant that has become an increasingly significant factor in the decline of forest. Ozone damage to forests has been reported worldwide, including in forests in eastern and western Europe [1] and throughout the USA [2]. In Japan, forest decline has been observed in several areas, including a decrease in number of Japanese fir (Abies firma) in Fukuoka Prefecture and of Japanese fir and Siebold's beech (Fagus crenata) on Mt. Tanzawa, Kanagawa Prefecture, Photochemical oxidants (especially ozone), acid fog and water stress are considered to be related to these declines [3, 4].

Serious damage and decline to Betula ermanii forests, Abies veitchii forests and Abies mariesii forests have been reported at Oku-Nikko region, a famous national park in Japan. In spring of 1983 simultaneous death of B. ermanii was observed at Mt. Mae-shirane [5] and over $100 \mathrm{ppb}$ concentrations of ozone have been recorded there in August 1995 [6]. However, no detailed investigations of the growth and decline of $B$. ermanii and long period (one growing season) measurement of ozone concentration have been conducted. The objective of the present study were to determine the current growth and decline of $B$. ermanii forest and ozone concentration and to explore the relationship between ozone concentration and B. ermanii forest decline.

\section{MATERIALS AND METHODS}

Study Site: The investigation was conducted from June to October 2000 and 2001 at Mt. Mae-shirane, (lat. $36^{\circ} 47^{\prime} \mathrm{N}$, long. $139^{\circ} 23^{\prime} \mathrm{E}, 2320 \mathrm{~m}$ above sea level), in the Oku-Nikko region, Japan. The soil type is wet podzol. The average annual precipitation is $1722 \mathrm{~mm}$ [7] and the average daily temperature in the growing season (May to September) ranged from 0.4 to $18.5^{\circ} \mathrm{C}$.

Field survey of Betula ermanii: To evaluate the growth situation of $B$. ermanii, 3 sampling sites (20X20 m) were established, one on the northwest-facing (NW)-facing slope and two on the southeast-facing (SE)-facing slope near the top of Mt. Mae-Shirane. Each tree at each site was sampled in July 2000 and 2001. In this study, we only showed the results of the investigation in July 2001, because the significant difference was not recognized in the results between investigations in July 2000 and 2001. Height was measured with an altimeter (271-3571, Showa Sokki Co., Japan) and Diameter at Breast Height (DBH) was measured at $1.3 \mathrm{~m}$ above the soil surface. The volume of the main stem was calculated from the following formula for a paraboloid [8]:

$Y^{3}=1 / 2 A_{b} h$

Where, $Y^{3}$ is the paraboloid volume, $A_{b}$ is the basal area $\left(\pi \mathrm{r}^{2}\right), \mathrm{r}=\mathrm{DBH} / 2$ and $h$ is height.

Stand density was determined by counting the trees and dividing the total number by the area of the sampling site $\left(400 \mathrm{~m}^{2}\right)$ and then converted into trees per ha. 
The level of tree decline was assessed as follows from the density of leaves and branches [9]:

Level 0: Tree grows well with good balance between densities of leaves and branches (Fig. 1).

Level 1: Leaves are slightly decreased in number and density compared with branches (Fig. 2).

Level 2: Leaves are remarkably decreased in number, because of increased withering of branches (Fig. 3).

Level 3: Tree has died (Fig. 4).

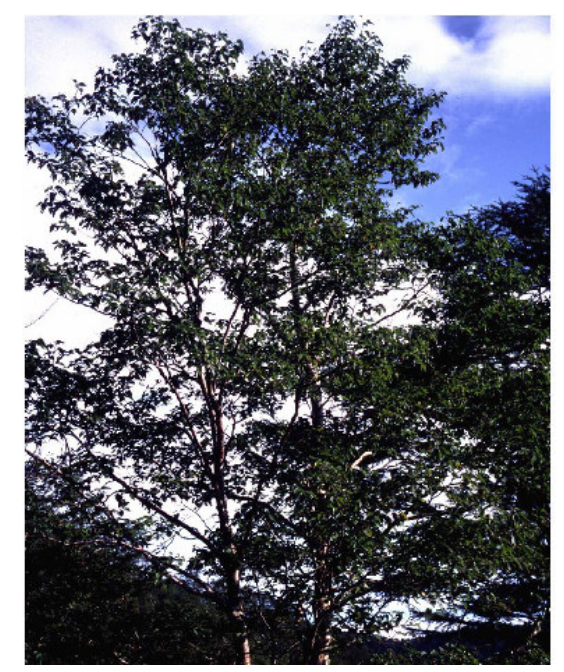

Fig. 1: Level 1: A Tree Grows Well with Good Balance on Density of leaves and branches

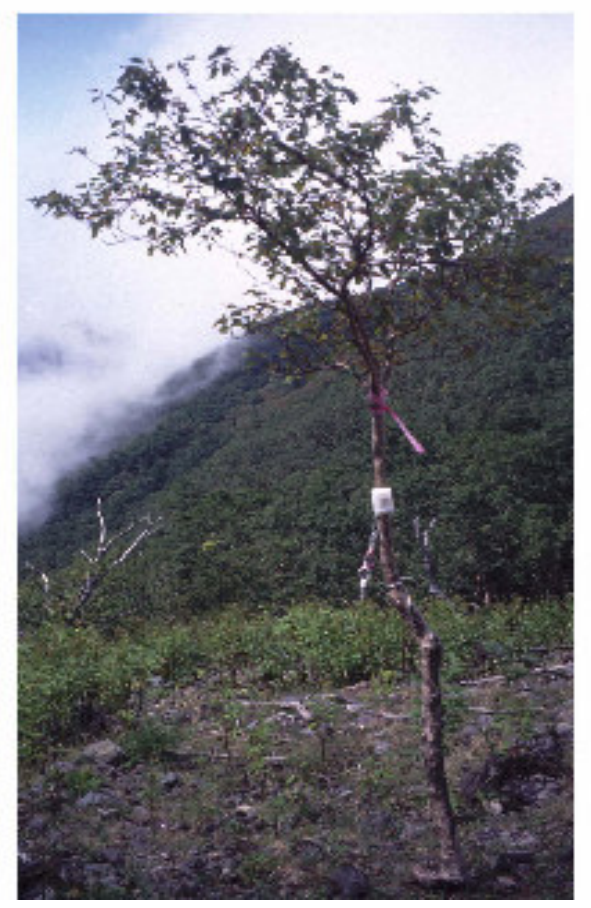

Fig. 2: Level 2: As Comparing with Branches, Leaves are Slightly Decreased

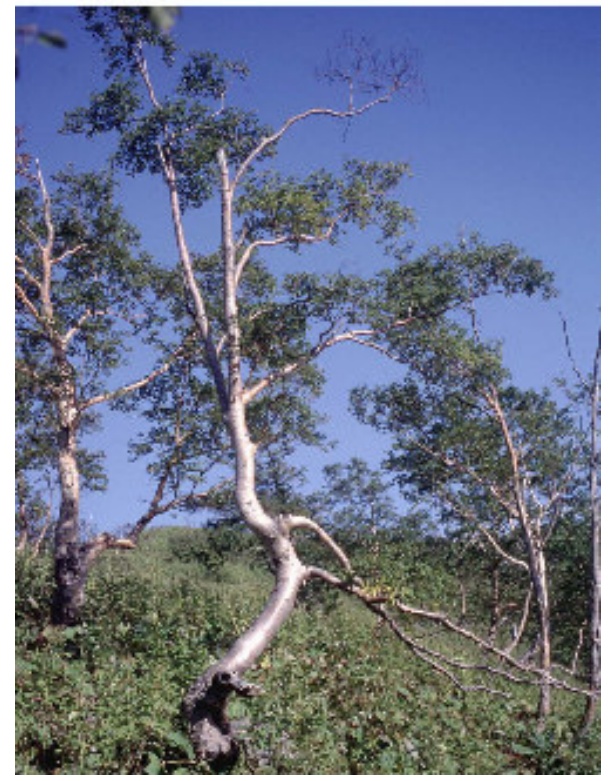

Fig. 3: Level 3: Leaves are Remarkably Decreased, Because of the Increase in Withering Branches

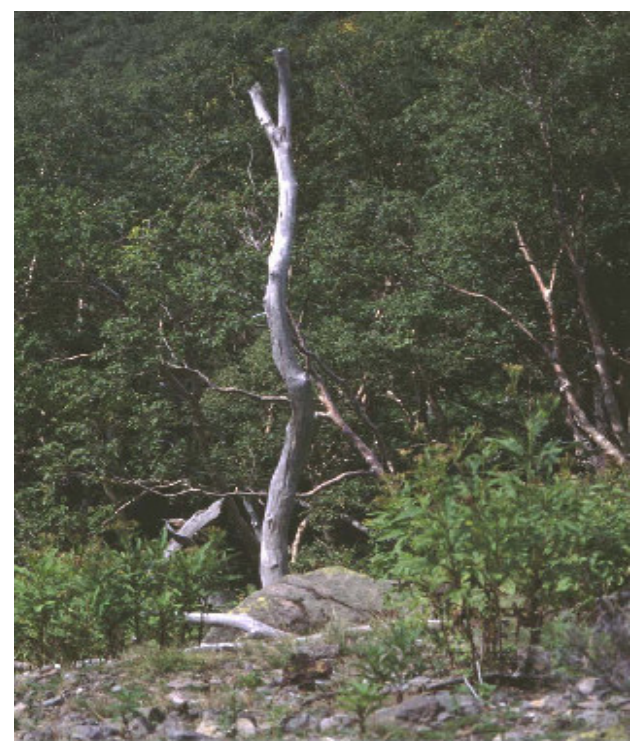

Fig. 4: Level 4: A Tree has been Died

Ozone Concentration Measurement: The Ogawa passive sampler [10] was selected to measure the ozone concentration, because this type of sampler does not require $\mathrm{AC}$ power, so it can be deployed virtually anywhere, thus making it ideal for atmospheric monitoring in remote areas. The sampler is constructed of a cylindrical Teflon body $19 \mathrm{~mm}$ in diameter and 30 $\mathrm{mm}$ in length. Two filters $14.5 \mathrm{~mm}$ in diameter impregnated with a nitrite solution are held in place on each end of the sampler by caps with holes that allow air to diffuse into the sampler. Ozone in air reacts with nitrite to form nitrate. The ozone concentration in the air 
can be calculated according to the equation of Cao and Hewitt [11]:

$C_{\text {ozone }}=\alpha_{\text {zone }} \times W_{N O 3} / T$,

Where, $C_{\text {ozone }}$ is ozone concentration in the air (ppb), $W_{N O 3}$ is $\mathrm{NO}_{3}$ mass (ng) and $T$ is exposure time (min) $\alpha_{\text {ozone }}$ is uptake rate ( $35.5 \mathrm{ppb} \square \mathrm{min} \mathrm{ng}^{-1}$ ).

Ten samplers were set at each sampling site and collected every 2 weeks from June to October 2001. The nitrate concentration was analyzed by ion chromatography (4500i, Dionex Co, USA) at the laboratory and then converted into $\mathrm{NO}_{3}$ mass $\left(\mathrm{W}_{\mathrm{NO} 3}\right)$.

The ozone concentration was also recorded continuously at the Oku-Nikko field station of the National Institute for Environmental Studies (the NIES station (lat. 36 ${ }^{\circ} 46^{\prime}$ $\mathrm{N}$, long. $139^{\circ} 24^{\prime} \mathrm{E}$ ), which is located 1450 above sea level and $3.5 \mathrm{~km}$ southeast of the investigation site. The concentration was recorded with a UV-photometric continuous ozone monitor (1006-AHJ, Ogasawara Co, Japan).

Statistical Analyses: All statistical analyses were performed with SPSS software [12]. Height, DBH, stem volume of $B$. ermanii and ozone concentration were compared between the NW-facing and SE-facing slopes by $\mathrm{t}$-test.

\section{RESULTS AND DISCUSSION}

Growth of Betula ermanii: A general description of the sampling plots is presented in Table 1. On the $\mathrm{NW}$-facing slope, DBH ranged from 0 to $14 \mathrm{~cm}$; DBH class $4-6 \mathrm{~cm}$ had the largest number of trees. On the SE-facing slope, DBH ranged from 0 to $10 \mathrm{~cm}$; DBH class $2-4 \mathrm{~cm}$ had the largest number of trees (Fig. 5). The mean DBH of trees on the SE-facing slope was significantly smaller than that on the NW-facing slope $(\mathrm{p}<0.05)$. The mean height and stem volume were lower on the SE-facing slope than on the NW-facing slope, but the differences were not significant. The stand density on the NW-facing slope was 8 times that on the SE-facing slope.

On the SE-facing slope, tree decline Level 0 was not observed and Level 1 accounted for about $45 \%$. On the NW-facing slope, Level 0 accounted for about $71 \%$ and Level 1 for about $5 \%$ (Table 2). These results indicate that the SE-facing slope had a worse growth situation and serious forest decline.

Ozone Concentration: Passive samplers were used in this study area where electrical power is inaccessible. The specificity and linearity of response of passive samplers were evaluated. Results obtained by passive samplers were compared with the corresponding data from a co-located UV-photometric continuous ozone monitor (1006-AHJ, Ogasawara Co, Japan) at National Institute for Environmental Studies. The adjusted $r^{2}$
Table 1: Mean DBH, Mean Tree Height, Volume of Stem and Stand Density in the Sampling Points

\begin{tabular}{lll}
\hline Plot & NW-facing & SE-facing \\
\hline Altituce $(\mathrm{m})$ & 2320 & 2320 \\
Aspect & northwest & southeast \\
Soil type & Wet podzol & Wet poszol \\
\hline Mean DBH $(\mathrm{cm})$ & 5.5 & $4.3^{*}$ \\
Mean tree height $(\mathrm{m})$ & 4.9 & 4.5 \\
Volume of stem $\left(\mathrm{m}^{3}\right)$ & $7.9 \times 10^{-3}$ & $4.7 \times 10^{-3}$ \\
Stand density $\left(\right.$ trees ha $\left.^{-1}\right)$ & 1450 & 175 \\
\hline
\end{tabular}

*:p<0.05 significant from tree growth at NW-facing slope

Table 2: The Decline Situation of Betula ermanii at South-east and North-west Slopes on Mt. Maesirane

\begin{tabular}{llcr}
\hline & $\begin{array}{l}\text { Decline } \\
\text { Degree }\end{array}$ & $\begin{array}{l}\text { No. of } \\
\text { trees }\left(400 / \mathrm{m}^{2}\right)\end{array}$ & Ratio \\
\hline South-east & Level 0 & 0 & 0 \\
& Level 1 & 5 & 45 \\
& Level 2 & 1.5 & 14 \\
North-west & Level 3 & 3.5 & 32 \\
& Level 0 & 54 & 71 \\
& Level 1 & 4 & 5 \\
& Level 2 & 0 & 0 \\
& Level 3 & 18 & 24 \\
\hline
\end{tabular}

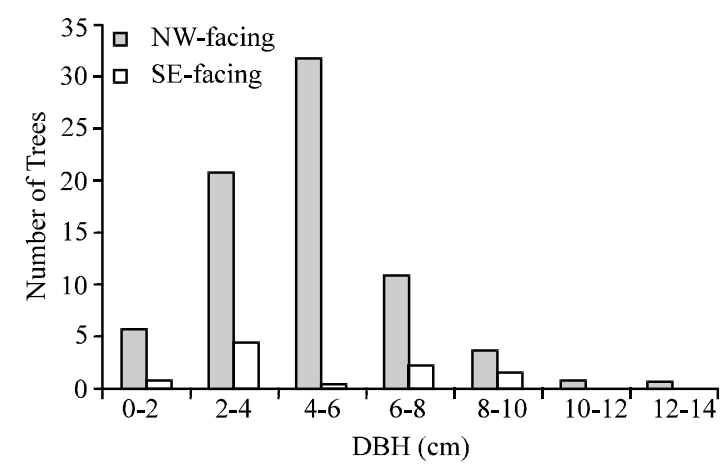

Fig. 5: DBH Class Frequency Distribution of Sampling Plots (trees $/ 400 \mathrm{~m}^{2}$ )

value was 0.98 with the $p$ value being 0.0001 . Through statistical analysis, we concluded that any differences in the results between passive sampling and continuous monitoring were solely due to their experimental error (Fig. 6)

The mean ozone concentrations from July through October 2001 were $36 \mathrm{ppb}$ on the SE-facing slope and 32 $\mathrm{ppb}$ on the NW-facing slope. At the NIES station during the same period, the mean ozone concentration reached $26 \mathrm{ppb}$, significantly smaller $(\mathrm{p}<0.05)$ than at the 2 study sites (Fig. 7). This significantly higher at the 2 study sites can be explained by the direct transport from Tokyo metropolitan area to the mountain of an aged air mass containing highly polluted air within the upper layer [6]. 


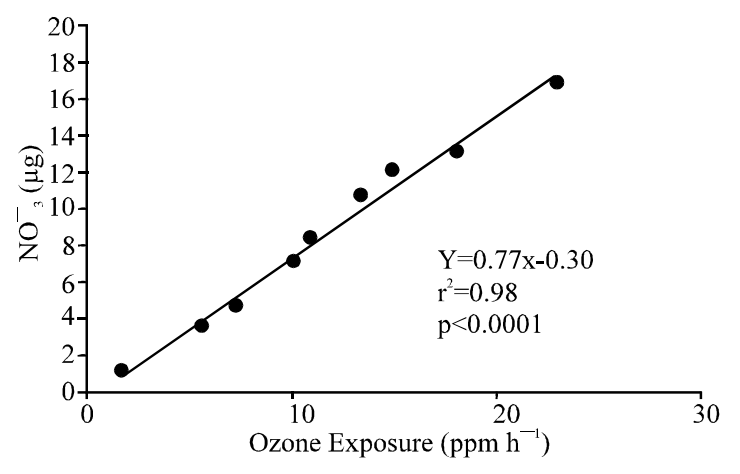

Fig. 6: Results of a Simple Linear Regression Analysis Between Ogawa Passive Sampler Mean Ozone Concentrations and Co-located UV-photometric Continuous Ozone Monitor

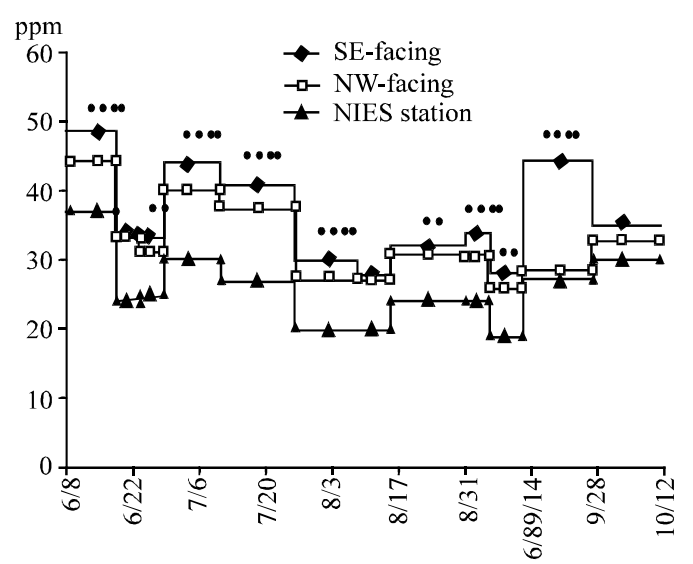

Fig. 7: Seasonal Change of Ozone Concentrations at SE-facing, NW-facing and NIES Station

The aged air mass containing highly polluted air transported by the see breeze from Tokyo collided with SE-facing slope first, then it is spread to some extent and arrived at the NW-facing slope. Therefore, it was considered as a major factor causing the slightly higher ozone concentration on the SE-facing slope. The result was similar to the findings of another investigation at Mt. Tanzawa, Kanagawa Prefecture [13]. The uptake of ozone by leaves in forest is widely knew, the amount of uptake may vary with species, tree size and soil moisture $[14,15]$. The amounts of ozone uptake by leaves in forest were reduced by low soil moisture and tree size $[15,16]$. In this study, the soil water content on the SE-facing slope ranged from 20 to $25 \%$ and was lower than on the NW-facing slope (25-30\%) during one growing season from July to October $[17,18]$. The tree size on the SE-facing slope was significantly smaller than that on the NW-facing slope $(\mathrm{p}<0.05)$ as mention above. Therefore, it was considered that the slightly higher ozone concentration on the SE-facing slope is also related to difference in the amounts of ozone uptake by plant.

The seasonal changes in ozone concentration were similar at all 3 sites (SE-facing slope, NW-facing slope and the NIES station); the concentration was highest in June, decreased gradually in July and August and then increased again in September and October. The seasonal change at Mt. Mae-Shirane was similar to the typical ozone change pattern at background levels in mid-latitude regions, so we considered the behavior of ozone in the stratosphere to be participative. This result was similar to the findings of another investigation at Nikko area [19].

The average ozone concentration during the period from 30 July to 6 August 2001 at the NIES station was 27 ppb, but a maximum instantaneous concentration of $>100 \mathrm{ppb}$ was recorded (Fig. 8). The highest daily ozone concentration was recorded mostly after 17:00, while the wind brew from the southeast, the direction of the Tokyo metropolitan area. Hatakeyama [6] analyzed the flux of pollutants from Tokyo to Mt. Akagi, which is about 30 $\mathrm{km}$ distant from Mt. Mae-Shirane. They recorded the highest ozone concentration at 18:00, at the same time as a highly polluted air mass from Tokyo arrived at the mountain. We believe that pollutants produced in Tokyo and transported to Mt. Mae-Shirane caused the high ozone concentration there.

In August 1995, ozone concentrations of $>100 \mathrm{ppb}$ were measured on the SE-facing slope [6]. In this study, the average ozone concentration during the period from 30 July to 6 August 2001 at the NIES station was $27 \mathrm{ppb}$, but a maximum instantaneous concentration of $>100 \mathrm{ppb}$ was recorded. The mean ozone concentration during this study period was ranked as SE-facing slope $>\mathrm{NW}$-facing slope $>$ NIES station. Therefore, we assumed that an instantaneous concentration of $>100 \mathrm{ppb}$ could have occurred on the SE-facing fcing slope.

Many studies indicate that ozone influences the growth, physiological functions (such as gas exchange rates and enzyme systems) and phenological characteristics of forest tree species native to Europe, North America and Japan [20-23]. To explain the relationship between ambient levels of ozone at Mt. Mae-Shirane and the growth situation of $B$. ermanii, we conducted an ozone exposure experiment at the NIES phytotron from June to October 2001 [17]. The B. ermanii seedlings (2 years old) were exposed to $50 \mathrm{ppb}$ daily average concentration (Max: 100 ppb; Min: $20 \mathrm{ppb}$ ) at $20 \pm 1^{\circ} \mathrm{C}, 75 \pm 5 \%$ R.H. The results showed that the dry weight growth of each organ and of the whole plant were significantly reduced, because of decreases in net photosynthetic rate, evapotranspiration rate and stomatal conductance. This result shows that ambient levels of ozone at Mt. Mae-Shirane can damage B. ermanii growth. We found serious forest decline on the SE-facing slope, although same levels of ozone were observed at both sites. It is generally accepted that forest decline is not related to 1 single factor, but to a mixture of stress factors, which can intensify each other $[21,24]$. Therefore, besides ozone stress, other stresses such as soil acidification, nutrient deficiency and soil moisture could affect the 


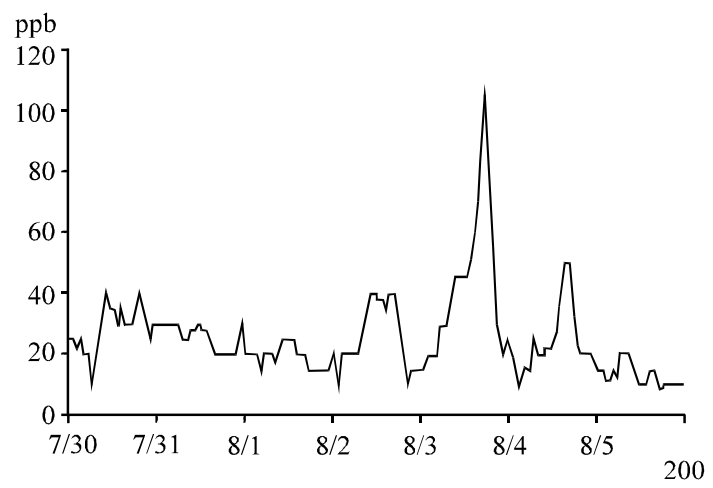

Fig. 8: Continuous Ozone Concentration at NIES Station

growth of B. ermanii. We found that soil $\mathrm{pH}$ on the SE-facing slope was significantly higher than that on the NW-facing slope and no deficiency of mineral nutrient ( $\mathrm{K}, \mathrm{Ca}$ and $\mathrm{Mg}$ ) or accumulation of $\mathrm{Mn}$ and $\mathrm{Al}$ in the soil or leaves of trees growing on the SE-facing slope [17, 18]. Therefore, the decline of B. ermanii growing on the SE-facing slope of Mt. Mae-Shirane cannot be explained by soil acidification or mineral nutrient deficiency (K, $\mathrm{Ca}, \mathrm{Mg}$ ) in soil and leaves.

Nitrogen is an essential element for a plant and has a close relation to the photosynthesis capacity. Hikosaka $e t$ al. [25] reported that maximum photosynthesis rate shows the high correlation with nitrogen content per unit leaf. On the SE-facing slope, nitrogen content in the leaves per this year shoot was significantly smaller than that on the NW-facing slope $(p<0.05)[17,18]$. The low nitrogen content was considered to be concerned in the bad growth of $B$. ermanii on the SE-facing slope. The nitrogen concentration and ratio of $\mathrm{C} / \mathrm{N}$ in the surface soil on the SE-facing slope was significantly lower than on the NW-facing slope $(p<0.05)[18]$. Fallen leaves and branches are the main source of the nitrogen returned to forest soil. The stand density on the SE-facing slope and amounts of leaves were significantly lower compared with the NW-facing slope, therefore amounts of fallen leaves and branches returned to the forest soil were no enough, the possibility that nitrogen will be lack on the SE-facing slope in the future was considered.

The forest floor on the SE-facing slope is covered with an annual herbaceous plant to the forest floor on the NW-facing slope being covered with bryophyte. Therefore, it is guessed that compared with NW-facing slope, the soil on the SE-facing slope tends to difficultly absorb the moisture by rain, the evapotranspiration from the forest floor is large and the water holding capacity is low. The soil water content on the SE-facing slope ranged from 20 to $25 \%$ and was significantly lower than on the NW-facing slope (25-30\%) during one growing season from July to October [17, 18]. Houston [26] suggested that pest infestations or fungal attacks following drought periods cause an overall deterioration of forest health. On the basis of these results, forest decline on the SE-facing slope cannot be explained by the soil acidification and mineral nutrient deficiency. On the other hand, the nitrogen deficiency in the leaves, water stress according to decline in the soil water content and exposure of relative high ozone concentration were considered as environmental factors causing the different growth situations of $B$. ermanii between the SE-facing and NW-facing slopes and causing the forest decline on the SE-facing slope. To clarify the B. ermanii forest decline in the Oku-Nikko region, continuous measurement of ozone concentration and other environmental factors and long-term field research on tree growth and decline will be necessary.

\section{CONCLUSIONS}

In this study, we measured the height, diameter at breast height and stand density of Betula ermanii trees and ozone concentration at Mt. Mae-Shirane. The current status of growth of Betula ermanii and long period ozone concentration were clarified for the first time and the relationship between ozone concentration and decline of $B$. ermanii trees on the mountain is discussed. The following conclusions are drawn:

* Height, DBH, stem volume and stand density were lower on the SE-facing slope than on the NW-facing slope, serious forest decline was observed on the SE-facing slope.

* The mean ozone concentrations from July through October 2001 were $36 \mathrm{ppb}$ on the SE-facing slope, $32 \mathrm{ppb}$ on the NW-facing slope and $26 \mathrm{ppb}$ at the NIES station, the changes in ozone concentrations were similar at all 3 sites.

* The ambient levels of ozone at Mt. Mae-Shirane can damage the growth of $B$. ermanii. Ozone is considered to relate to decline of $B$. ermanii forest at Mt. Mae-Shirane.

\section{ACKNOWLEDGEMENTS}

We thank Mr. T. Tamura, Tokyo University of Agriculture and Technology, for his help in field investigation. We also thank Professor T. Izuta, Tokyo University of Agriculture and Technology, for his valuable comments, discussion and encouragement. This work was part of a research project on quantitative analysis of terrestrial ecosystem decline related to acidic/oxidative substances, funded by Global Environment Research Fund, Ministry of the Environment, Japan.

\section{REFERENCES}

1. Rennenberg, H., A. Polle and M. Reuther, 1997. Role of Ozone in Forest Decline on Wank Mountain. In: Sandermann, H., Wellburn, A. R., Heath, R.L., Forest Decline and Ozone: A Comparison of Controlled Chamber and Field Experiments, Ecological Studies 127. Springer-Verlag, Berlin, pp: 135-162. 
2. Miller, P.R., R. Guthrey, S. Schilling and J. Carrooll, 1998. Ozone Injury Responses of Ponderosa and Jeffrey Pine in the Sierra Neveda and San Bernardino Mountain in California. In: Bytnerowicz, A., Arbaugh, M. J., Schilling, S., International Symposium on Air Pollution and Climate Change Effects on Forest Ecosystems. USDA Forest Service Pacific Southwest Research Station, Riverside, CA, USA.

3. Suda, R., Y. Sugi, A. Utsunomiya, O. Oishi and K. Hamamura, 1992. Decline of Japanese fir trees in Mt. Homan, Fukuoka Prefecture. J. Resources and Environ., 28: 1344-1348.

4. Nakane, K., H. Sakugawa and M. Igawa, 2000. Air pollution and tree damage in the pine or fir forest decline area at Hiroshima or Kanagawa Prefecture, Japan. Japanese J. Ecol., 50: 319-324.

5. Tanimoto, T., Y. Liu, T. Satomich, T. Ohkubo and K. Nihei, 1996. Forests damage and its environmental condition in the Okunikko, Ashio and Akagi mountainous region, northern Kanto district, central Japan. Japanese J. Forest Environ., 38: 1-12.

6. Hatakeyama, S., 1999. Forest decline and acidic/oxidative substances at Oku-Nikko region. Japanese J. Environ. Sci., 12: 227-232. (In Japanese).

7. Shindo, J., T. Fumoto and N. Oura, 2002. Quantitative analysis of terrestrial ecosystem decline related to acidic/oxidative substances. Study Report of Global Environment Research Fund, pp: 106-126.

8. Leege, L.M. and P.G. Murphy, 2000. Growth of the non-native Pinus nigra in four habitats on the sand dunes of Lake Michigan. Forest Ecol. Manage., 126: 191-200.

9. Japan Environmental Agency, 1993. Investigation of Acid Rain, pp: 12-13. Tokyo, Japan.

10. Krupa, S.V. and A.H. Legge, 2000. Passive sampling of ambient, gaseous air pollutants: An assessment from an ecological perspective. Environ. Pollution, 107: 31-45.

11. Cao, X.L. and C.N. Hewitt, 1994. Build-up of artifacts on adsorbents during storage and its effect on passive sampling and gas chromatography-flame ionization detection of low concentrations of volatile organic compounds in air. J. Chromatography A, 688: 368-374.

12. SPSS Japan Inc., 2002. SPSS ${ }^{\circledR}$ Base 11.5J User's Guide, pp: 279-287. Tokyo, Japan.

13. Maruta, E., K. Shima, K. Horie, M. Aoki, Y. Dokiya, T. Izata, T. Tosuka, H. Yokoi and T. Sakada, 1999. Decline of Fagus crenata forest and acid deposition at Hinokiboramaru. Mt. Tanzawa. Environm. Sci., 12: 241-250.

14. Van Hove, L.W. A., M.E. Bossen, F.A.M. De Bok and C.A.M. Hooijmaijers, 1999. The uptake of $\mathrm{O}_{3}$ by poplar leaves: The impact of a long-term exposure to low $\mathrm{O}_{3}$ concentrations. Atmospheric Environ., 33: 907-917.
15. Patterson, M.C., L. Samuelson, G. Somers and A. Mays, 2000. Environmental control of stomatal conductance in forest trees of the Great Smoky Mountains National Park. Environ. Pollution, 110: 225-233.

16. Hanson, P.J., L.J. Samuelson, S.D. Wullschleger, T.A. Tabberer and G.S. Edwards, 1994. Seasonal patterns of light saturated photosynthesis and leaf conductance for mature and seedling Quercus rubra L. foliage: Differential sensitivity to ozone exposure. Tree Physiol., 14: 1351-1366.

17. Feng, Y. W., H. Shimizu, N. Ohta and T. Izuta, 2002. Quantitative analysis of terrestrial ecosystem decline related to acidic/oxidative substances. Study Report of Global Environment Research Fund, pp: 141-155.

18. Tamura, T., T. Yonekura, T. Nakaji, Y.W. Feng, H. Shimizu and T. Izuta, 2002. Field survey on phenological characteristics and leaf components of Betula ermanii Cham. and soil chemical property around Mt. Mae-Shirane, Oku-Nikko, Japan. J. Japanese Soc. Atmospheric Environ., 37: 320-330.

19. Fujinuma, K., 1991. Concerning the weather and atmospheric environment at Okunikko region. Environments and Biota of the Nikko Area: Reports From Okunikko Field Station, National Institute for Environmental Studies, Japan.

20. de Vries, W., J.M. Klap and J.W. Erisman, 2000a. Effects of environmental stress on forest crown condition in Europe. Part 1: Hypotheses and approach to the study. Water, Soil and Air Pollution, 119: 317-333.

21. Van Leeuwen, E.P., C.M.A. Hendriks, E. de Joung, J.W. Erisman, J.M. Klap and W. de Vries, 2000. Effects of environmental stress on forest crown condition in Europe. Part 2: Estimation of stress induced by meteorology and air pollutants. Water, Air and Soil Pollution, 119: 335-362.

22. Panek, J.A., M.R. Kurpius and A.H. Goldstein, 2002. An evaluation of ozone exposure metrics for a seasonally drought stressed ponderosa pine ecosystem. Environ. Pollution, 117: 93-100.

23. Shimizu, H., Y. Fujinuma, K. Kubota, T. Totsuka and K. Omasa, 1993. Effects of low concentrations of ozone on the growth of several woody plants. J. Agr. Met., 18: 723-726.

24. de Vries, W., G.J. Reinds, J.M. Klap, E.P. Van Leeuwen and J.W. Erisman, 2000b. Effects of environmental stress on forest crown condition in Europe. Part 3: Estimation of critical deposition and concentration levels and their exceedances. Water, Soil and Air Pollution, 119: 363-386.

25. Hikosaka, K., Y. Hanba, T. Hirose and I. Terashima, 1998. Photosynthetic nitrogen use efficiency in leaves of woody and herbaceous species. Functional Ecol., 12: 896-905.

26. Houston, D.R., 1992. A Host Stress Saprogen Model for Forest Dieback Decline Diseases. Forest Decline Concepts, St. Paul, Minnesota, USA, pp: 3-25. 